\title{
CENTERING RACE AND ETHNICITY-RELATED ISSUES IN SOCIAL SCIENCES CURRICULA
}

\section{Joseph F. Sheley \\ California State University, Sacramento}

A 2002 review of the course requirements and electives of Economics, History, Political Science, and Sociology programs in thirty randomly selected state and private, "doctoral-level" and "masters-level" institutions produced 201 courses relating to the study of race-and ethnic-related issues. Only two courses (History offerings on a single campus) were required for completion of a major. While some departments offered "concentrations" with mandated content, the concentrations themselves were elective. Diversity in America today is a truly important component of social (re)organization and change and, thus, a major source of social friction. Why is it, then, that students, those majoring in the social sciences in particular, are able, by uninformed or informed choice, to complete a degree with but cursory attention to the topic? This essay addresses the reasons for relegation of diversity-related issues to option- 


\section{Ethnic Studies Review Volume 26: 2}

al status and argues that the situation can and should be reversed.

It is difficult to understate the significance of race and ethnicity in contemporary American society. To open the newspaper each day is to wrestle with diversity-related variables, in terms of both causes and effects, as among the more powerful and enduring social forces of our time. National and state trends and policy decisions are experienced in a variety of ways at the community level and, in turn, shape those same trends and policies. Consider the following examples of persistence of race- and ethnicity-related social patterns that have been the subject of recent media attention:

- Race and ethnicity remain linked to health, education, occupation, residence, and even criminal justice choices, chances, and outcomes beyond the effects of socioeconomic status.

- Racial and ethnic integration of K-12 schools has decreased since its apex in the 1970s; presently, 70 percent of African American and Latino students attend predominantly minoritypopulated schools.

Consider also elements of social change reported by the media: - U.S. Census data indicate that, in 2000, 2.4 percent of the American population identified itself as having multiple racial and ethnic backgrounds.

- It is estimated that 30 percent of second-generation Latino Americans and Asian Americans enter marriages with persons from other racial and ethnic backgrounds.

- The fastest growing population subgroup in America is Latino (1 in 20 Americans in 2000), and this fact is rapidly reshaping political party agendas.

- Were it not for immigration from Latin America and the Pacific Rim, Many states, California in particular, would not have increased their workforces between 1990 and 2000 sufficiently to have enjoyed a period of major economic expansion.

Finally, consider racially- and ethnically-related social and political stresses described by the media:

- Racial and ethnic tensions linked to education and immigration patterns in California in the 1990s spawned Propositions 
209 (prohibiting "preferences" in any activities derived from state funding), 187 (aimed at curbing social benefits and services to illegal aliens), and 163 (promoting English only in schools). - In December, 2002, insensitive remarks regarding the status of segregation in U.S. history cost Trent Lott ( $\mathrm{R}-\mathrm{Miss}$ ) his position as Senate Majority Leader.

- In January, 2003, President Bush publicly joined the opposition toward the University of Michigan's use of race as an important factor in admissions decisions, a matter that became the focus of a major U.S. Supreme Court case and significant media and political commentary and that was decided in favor of the University.

- In June, 2003, President Bush issued an executive order forbidding the use of racial profiling as a tool of law enforcement by federal agencies, except as it relates to anti-terrorist efforts.

The issues captured in the above examples (by no means an exhaustive inventory) are neither subtle nor trivial. They indicate clearly that, while interesting, beautiful, and part of our national heritage, diversity in America is today also a truly important component of social (re)organization and change and, thus, a major source of social friction. The implications of life in a diverse society are, for all practical purposes, significant and unavoidable.

\section{Social Science Research and Diversity}

Understandably, social-scientific research attention to the topic of race and ethnicity in America is abundant. Social scientists are well aware of patterned differences in attitudes, behaviors, and experiences across segments of our population. Those differences often are manifested at both individual and aggregate levels along racial and ethnic lines. Some of these differences may be a function of socioeconomic status differentiation, and some may not (always a useful empirical question by which to teach students more about a given discipline). Not all social lives at all times are arranged directly around such differences and related stereotypes of them. It is debatable, for example, that they are sufficiently patterned to constitute significant cultural differentiation (as in assertions that ours is or is becoming, 


\section{Ethnic Studies Review Volume 26: 2}

literally, a multicultural society). Yet, few social scientists would argue that their effects on persons making their way through life are inconsequential. Few would argue as well that such differentiation has not fostered, for over two centuries, serious, persistent social friction in the United States.

An extraordinary number of books addressing race- and ethnicity-related matters is published each year by social scientists. Internet searches of titles pertinent to "Race in America" offered by such publishers as University of Chicago Press, University of North Carolina Press, and University of California Press produce literally hundreds of entries. In a related vein one in four articles recently published in the major, general journal of the American Sociological Association (American Sociological Review [Vol. $67,2002])$ pertained to the topic of race and ethnicity in America. The corresponding fraction of coverage within the discipline of History was one in nine articles (American Historical Review [Vol. 107, 2002]), of Political Science, one in eleven articles (American Political Science Review, Vol. 96, 2002] ), and of Economics, one in twenty articles (American Economic Review [Vol. 92, 2002] ). Each of these disciplines also has numerous more specialized research publications that devote considerably more attention to issues of race and ethnicity.

\section{Social Science Curricula and Diversity}

Against the backdrop of popular, political, and social-scientific concern with contemporary racial and ethnic diversity, one would expect to find serious university curricular focus on the same matters. To a certain degree the expectation is met. College and university campuses today more often than not address diversity-related tensions in society through curricula that are responsive to and appreciative of the social and cultural experiences of students from traditionally underrepresented populations. They generally seek to heighten student awareness of differences in the way that people(s) experience the world, to engender respect for the beauty and functionality inherent in heterogeneity, and to provide a welcome environment for students of all backgrounds. Some view this effort as worthy, others as a politically correct distraction. In either case various gen- 
eral education requirements and elective courses within majors result in at least some exposure to diversity-related issues across the student's academic career. Many argue too that "cultural majors" such as Ethnic Studies and Women's Studies have been designed to provide options for the relatively small population of students with admirably greater than ordinary interest in matters of diversity.

Exactly how much exposure to diversity-related issues actually occurs among students who do not pursue a "cultural major," however, is difficult to discern since choices of elective courses within majors rarely are tracked, and general education requirements in this area usually are loosely knit, expansive, and designed in great part to spread the wealth of enrollment across campus units. In most universities, for example, dozens of courses, ranging from martial arts to Civil War history, commonly fulfill the institution's (in most cases, lone) "multicultural" course requirement. It is doubtful that many universities could describe in anything resembling learning-outcomes terms, what their students should master in the way of a systematic understanding of such a controversial matter as diversity in this society. Indeed it is a reasonable proposition that students in most universities are able by uninformed or informed choice to complete a degree with but cursory attention to the topic.

The exception to the "hit or miss" approach to curricular coverage of racial and ethnic matters, it might be assumed, would be found among the social sciences whose practitioners, as noted above, devote extensive research energy to such matters (as well as grappling routinely with the implications of affirmative action in faculty hiring and student admissions). Therefore, the reasonable empirical question: What place does racial and ethnic differentiation actually now occupy within social science major (as opposed to general education) curricula?

The answer: It is accorded elective coverage. A review of the 2002 course requirements and electives of Economics, History, Political Science, and Sociology undergraduate programs in 30 state and private doctoral and master's-level institutions, randomly selected from a comprehensive list of U.S. uni- 


\section{Ethnic Studies Review Volume 26: 2}

versities, 1 produced 201 courses relating to the study of race- or ethnic-related issues. Exactly two (History courses on a single campus) were required for completion of a major. The remaining 197 elective possibilities were varied, topical, and excellent: race and economy, immigration and assimilation, assimilation and political power--the list was long and impressive. Still, they were optional. Some departments sought to split the difference between elective and requirement. One history program in the sample, for instance, required its majors to choose any two from a list of four courses, two dealing with U.S. and two with African American history. Some departments offered "concentrations" with mandated content (e.g., a four-course "race and ethnicity" sequence), but the concentrations themselves were elective.

Thus, while much of related substance surely is contained in numerous, more general departmental offerings (e.g., modern social problems, contemporary political issues), it clearly is possible for a student to major in most social-science disciplines without taking a single course that directly, pointedly, and primarily addresses the implications of life of in a highly heterogeneous society. Students can move from campus to real world lacking a conceptual framework (even a partial one produced by immersion in one given discipline rather than in another) to a complicated set of intense and daily pertinent social relationships and to legislative and policy agendas at the local, state, and federal levels that have direct implications for, among other elements of collective life, employment, education, and residence.

\section{Potential Curricular Revision}

The curricular marginalization of diversity issues that otherwise claim professional research attention likely traces less to overt hostility to the topic of diversity than to traditional ways of defining curricular domain. Like their students, social scientists read the newspaper and confront issues such as the changing composition of the population, shifts in power and wealth, problematic delivery of social services, shrinking access to health and education resources, and persistent cultural biases. Yet, while these clearly fit our social-scientific interests, they are packaged within our curricula as contemporary "applications" expected to 
emerge via examples in courses on disciplinary "basics." Differential life chances and attendant social tension linked to ascribed social characteristics traditionally are considered "applied" rather than "basic" foci.

Easily as importantly, the situation also traces to anxiety. The curricular focus upon diversity-related issues involves difficult material delivered to people of different backgrounds, interests, and levels of experience. Hard questions are asked; offense is often taken; stereotypes come to the fore in the classroom. Most faculty members understandably are not anxious to accept such a challenge. It is stressful, and stress is relieved more easily by nesting "diversity relations" within courses focused upon multiple social issues and problems (e.g., crime, environmental threats, educational reform). Ironically, the stress that comprises the pedagogical hurdle in question makes the case rather well that diversity-related issues are among the most sensitive in this society. It is difficult to reconcile this with the view that these issues do not merit greater than elective attention within the social sciences. And we can wonder as well why the academy that defends relatively free expression of ideas and even conflict as necessary to constructive discourse has such trouble with this particular set of ideas and conflicts.

Could we bring diversity-related issues more directly into our social science major programs? Undoubtedly and without radical substantive (as opposed to ideological and pedagogical) change, since most programs now feature elective coverage of such issues. The difference between extant and revised curricula would be found in the greater and mandatory emphasis upon the implications of ascriptive statuses, cultural assimilation, and socioeconomic conflict and change, historically and contemporarily, than is now the case. A tremendous amount of what we consider of theoretical, methodological, and substantive importance in our disciplines can be addressed in courses that focus upon the various social implications of "differences" - including the very proper scientific question of degree of "cultural variation" across contemporary American subpopulations. The partial restructuring of the typical social science major curriculum such that race- and ethnic-related issues (and, potentially, those per- 


\section{Ethnic Studies Review Volume 26: 2}

taining to other ascribed statuses implicated to a high degree in contemporary social organization and change) were designated "basic" as opposed to "applied" (usually "elective"), could in an of itself represent an important device by which to transmit to students the building blocks of a discipline.

Importantly, not every discipline can address all aspects of diversity-related issues in contemporary society. ${ }^{2}$ Each can, however, bring a particular, systematic approach to examining various of those aspects. Perhaps the decision about whether and how best to address this possibility should begin with departmental discussions of the significance of the "social difference" variable in those elements of the world captured by the department's discipline. Rarely do we list and prioritize the substantive topics that we might and might not include in our major required courses. The discussion surely will lead at least one member of the department to ask: "What is more worthy of study within our discipline than this?" It is difficult to imagine diversity-related issues failing to make the list of the top five topics.

\section{Conclusion}

Momentarily sorting out theoretical and ideological issues, we return to the basic premise of this discussion: it is entirely possible for students to proceed through their college educations with but scant and likely unsystematic attention to the implications of racial and ethnic diversity in this society. This occurs despite the significance of diversity-related matters (including, on some campuses, admissions policies) in the students' everyday lives. Perhaps the relative social harmony of campus life, in which few people knowingly, purposefully, and overtly would discriminate against anyone on the basis of ascribed characteristics, blinds us to the significance of racial and ethnic conflict outside (and, truth be told, inside) the ivory tower. We have addressed our obligation (if, indeed, we view it as such) to attend to diversity-related conflict as a social fact by assigning it to the general education curriculum (usually as a matter of one-shot exposure) and by providing students with "choices" by which to increase their level of expertise in this area. The outcome of this decision is apparent when we sketch real-world issues on a transparency. 
We place diversity-related conflict near the center. When we overlay this transparency with one that captures what we address in our college and university curricula, including those in the social sciences, we find diversity-related conflict nowhere near center. We have marginalized and, in many senses, downplayed the significance of a crucial element of contemporary social life. It is time to discuss priorities. Whatever its result, such a discussion at the very least will serve better to sharpen our own senses of our various disciplines such that students who choose them as major subjects can only benefit.

\section{Notes}

1 The 30 institutions were selected through use of a table of random numbers applied to a comprehensive list of "Category I (doctoral)" and Category II (master's) universities maintained by the AAUP. (www.chronicle.com/stats/aaup/2002). "Category I" universities are "characterized by a significant level and breadth of activity in and commitment to doctoral-level education as measured by the number of doctorate recipients and the diversity in doctoral-level program offerings." "Category IIA" universities are "characterized by diverse postbaccalaureate programs (including first professional), but not engaged in significant doctoral-level education.." Catalogs of the sampled universities were examined, online, regarding courses on race- and ethnicity-related issues offered by the departments of Economics, History, Political Science, and Sociology. Each course was identified as either "required" or "not required" of all students choosing the major.

2 Lest we focus inordinately upon the social sciences, it is important to acknowledge that these same conversations can and should be had within the arts, humanities, and sciences. How important is it that English or Art majors, for example, be exposed to the literatures and art forms of multiple segments of our population? Of no more than elective importance? What would happen were all English majors required to take a course on "contemporary African American authors"? Similarly, given myths and misconceptions held within this society, what would be the outcome of a required interdisciplinary course for science majors regarding the genetic facts about race? 